\title{
Review on the Evolution of Platform Research from the Perspectives of Management and Economics
}

\author{
Xin Jiang ${ }^{1 *}$ \\ ${ }^{1}$ Party School of Yunnan Committee of C.P.C (Yunnan Academy of Governance), Yunnan, Kunming ,650000, China \\ *Corresponding author. Email:80619358@qq.com
}

\begin{abstract}
The rising of platform economy provokes intense interests of scholars to do exhaustive research on it, which lasts 30 years and be viewed as the frontier of industrial economics and management. Although the research of platform originated from two areas and each of them developed on different practices and theories, the two research approaches demonstrated intercrossing with the development of research gradually. In this paper, it lists the paths of evolution on platform research and the fruits of both by documentary analysis. The intersects and integration between management and economics have been found, after comparing each of their approaches to research and results, on which based the future research on platform economics has been pointed out in the end. No matter in management or economics perspectives, this paper could provide a useful basis that may invoke inspiration for further study on the platform.
\end{abstract}

Keywords: Platform economics, Platform structure, two (multi)-sided markets.

\section{INTRODUCTION}

Research on platform economy can be divided into three fields according to the time of initiation and the category to which it belongs. First, since the 1990s, the research related to manufacturing engineering design in the field of management has mainly focused on platform manufacturing, whose production mode change with platform structure, and focused on the process and mechanism of improvement of manufacturing efficiency. Second, the related research on market reforms in the field of economics that began in the early 21 st century focused on the intrinsic properties and mechanisms of the platform market, and gradually extended to the governance issues brought about by the platform. The combination of these two fields forms the main content of platform economics. The third is related research on platformization recently started in 2015.

Although the research of platform originated from two areas and each of them developed on different practices and theories, the two research approaches demonstrated intercrossing with the development of research gradually. Product platform within intra-firm which first come to the research of management expands to industrial platform based on the concept of technology platform and to business eco-system with the central thought of platform, meanwhile multi-sided markets that differ from traditional single-sided markets be treated as the subject by economists who pay enough attentions to its features, functions, and mechanism. In this paper,we discuss the path of evolution about the platform research, hoping that it can give some ideas for future research.

The second and third sections of this article will respectively describe the two evolutionary contexts of platform economics research. Section IV focus on the relevant platformtazion that as a main way of industry transformation today. Section $\mathrm{V}$ summarizes and compares the research results of the two fields, and gives comment on future research and development. 


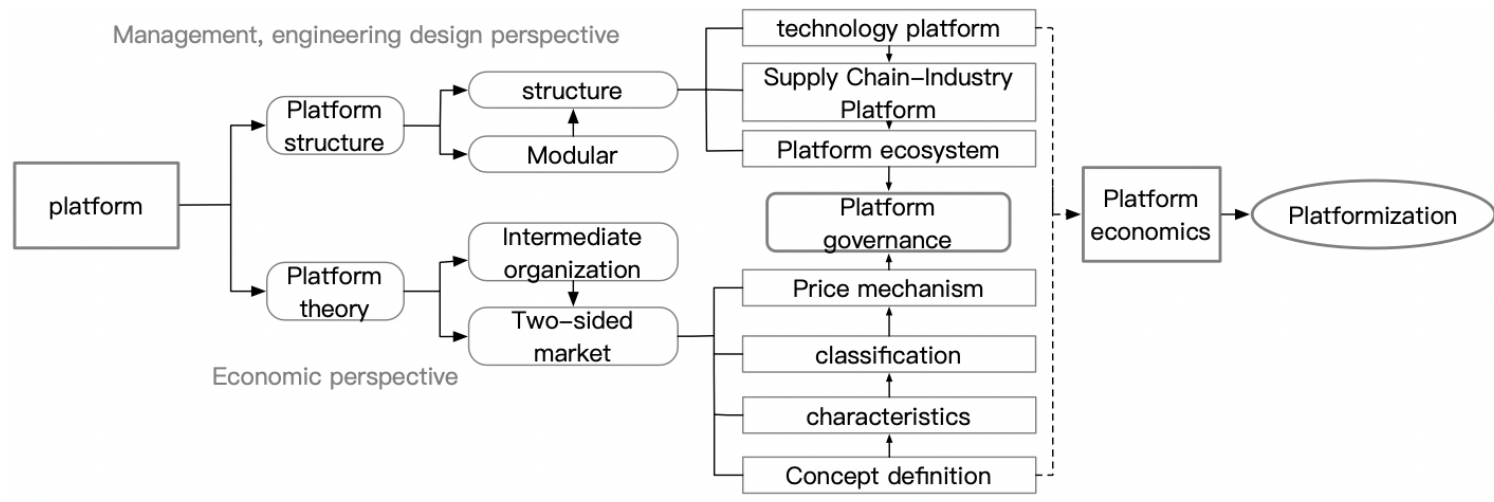

Figure 1 Context of Platform Economy Research

\section{PLATFORM THEORY FROM THE PERSPECTIVE OF MANAGEMENT}

The concept of platform originated in management science. It first appeared in the literature that about new products development. Wheelwright \& Clark (1992) [1]first proposed this concept and believed that the platform can meet a set of core user needs. At the same time, the adjustment can be achieved by adding some modules, replacing or removing some features. McGrath (1995) [2]believes that a platform is a collection of common elements, especially technical elements that can be used in a series of products. Meyer \& Lehnerd (1997) [3]defined a platform as a series of subsystems and interfaces. These subsystems and interfaces can be combined according to certain rules to form a general design structure, thus forming a product production line. Krishnan \& Gupta (2001)[4] simply defined the platform as a common component and systemic asset in the product family. Based on this, Muffato \& Roveda (2002) [5]deepened the understanding of the platform from the perspective of efficacy and believed that the platform could arrange a series of subsystems and interfaces to make product development proceed smoothly according to destination designs.

\subsection{Product technology platform}

The platform was put forward on the research of product production line from the perspective of management, so the product platform became the first research object. The product platform is a universal production structure composed of a core system and various interfaces that can be matched with the system. Different products with small differences in characteristics can be produced by this universal production structure (Meyer \& Lehnerd, 1997[3]). In the 1990s, many scholars did extensive research on product platforms, such as platform investment (Kogut \& Kulatilaka[6], 1994), platform technology (Kim \& Kogut[7], 1996), and platform thinking (Sawhney[8], 1998), And follow-up research on platform product planning and management practices (such as Sanderson \& Uzumeri[9], 1995; Meyer \& Lehnerd[3], 1997;
Robertson \& Ulrich[10], 1998; Krishnan \& Gupta[4], 2001).

\subsection{Supply Chain Industry Platform}

In the information age, the boundaries of enterprises with the help of communication technology and network equipment have gradually become blurred, and the concept of platforms has begun to gradually extend from the inside of the enterprise to the outside. In addition to the acquisition of economies of scale, companies are constantly striving to find economies of scope in production and innovation (Panzar \& Willig,[11] ; Teece[12], 2006). The behavior of these companies is fully reflected in industries related to engineering design flow (Such as automobile manufacturing, aircraft engine manufacturing, and electronics manufacturing), all the same can be seen in the organizational design model. For example, early research found this manufacturing platform inside the enterprise and confirmed how this manufacturing platform can quickly be used in the enterprise (Zirpoli \& Becker[13]).

Due to the platform principle is applied to the outside of the enterprise by the individual enterprise, the traditional linear supply chain structure has gradually become a radial or even a networked one, and the industry has been re-integrated and shaped. Pursuing the control of technology and obtaining technology "rent" from the perspective of technology strategy are the core principles of the operation of supply chain platforms and industrial platforms. From the perspective of economic logic, the reuse of modules in the platform, although it is a simple step, has enpower all the system through various combinations of core modules and variable modules. The relatively stable components in the platform can usually extend the depreciation time of fixed assets by increasing the amount of production and the use of shared production equipment for product families. In addition, assets occupied by complementary components can also be fully utilized (Such as product distribution; channels and after-sales technical services, etc.) in order to achieve economies of scale. At the same 
time, the system-level platform can effectively reduce the cost and risk of the technology needed to develop products for different customer groups (different modules in the industry platform, while carrying out technological development, and finally selecting the most effective module to avoid the risk of development failure of the entire system (Hatch[14], 2000)) in order to achieve economies of scope.

\subsection{Platform ecosystem}

Due to the continuous expansion of platform thinking in the production system,platform strategy has gradually become the preferred strategy of emerging companies, at the same time established companies have also begun to use platform strategy for their own transformation. From the perspective of engineering design, the platform system has an important attribute that can be evolved (upgraded) (Baldwin \& Woodard[15], 2009), and can adapt to the external environment to make unforeseen changes. From the perspective of ecology and economics, evolution is maintained through the dynamic effects of mutation mechanisms and the selective retention of dominant forms. In the environment of Internet information technology, platforms continue to evolve under the dynamics of corporate competition. The operation of the technology platform is driven by the Internet,which penetrates into a wider corporate network, although there is no necessary buyer-seller relationship among these companies connected by the platform. This extensive production network (Adner \& Kapoor[16], 2010 ) is called innovation ecosystem, or complex innovation ecology (Dougherty[17], 2017). Any one of these industrial platforms can be regarded as a "brick" in the entire production system, providing the necessary specific functions for the entire technical system. The function of each "brick" is the cornerstone of the operation of other enterprises, and the networked organization of this brick in the innovation system enables complementary products, technologies or services come into being(Gawer[18], 2009).

\section{PLATFORM THEORY FROM THE PERSPECTIVE OF ECONOMICS}

The research on platform theory began at the turn of the century. At that time, there was a theoretical and empirical debate, which triggered a series of international bank card network antitrust cases in the United States, Europe, and Australia. Since then, a series of industrial organization economics documents (Rochet \& Tirole[19], 2003; Caillaud \& Jullien[20], 2003; Ambrus \& Argenziano[21], 2004; Armstrong[22], 2010; Chakravorti \& Roson[23], 2006) have studied the theory of bilateral markets, including definitions , characteristics, operating mechanism, etc.; these papers research on the subject behavior of bilateral markets, including pricing strategies, market rules, platform ownership, competition and regulation. The field of this research focus on the pricing mechanism of the two sides of the platform, and simulate the actual two-sided platform game competition through modeling different platform competition modes.

\subsection{Definition of the two-sided market}

From the perspective of economics, the platform is regarded as a special embodiment of the market. Its main function is to realize transactions between different types of customers. If there is no platform, these transactions are difficult to achieve. Such platforms are called two-sided markets, multi-sided markets or multi-sided platforms (Rochet \& Tirole[20], 2003, Evans[24], 2003; Rysman[25], 2009 ).

Different scholars have defined the definition of bilateral markets from different perspectives, which are mainly divided into two categories: one is the explanation based on the mechanism of network externality (Armstrong[22], 2010). Interactions (transactions) involving two groups of customer carried out through the platform. In this transaction process, the level of benefit of a group of customer depends on the scale of the interaction (transaction) group at the other end of the platform. The other is an explanation based on the price structure, which uses the price structure to determine whether it belongs to a two-sided market. The non-neutral price structure is reflected in the fact that different fees charged to different customer groups on the platform will have different effects on transaction volume (Rochet \& Tirole[26], 2010). Evans et al. (2008) define bilateral markets from the two dimensions of price and network externalities: there are commercial pricing and business models on both sides of the platform that are susceptible to indirect network externalities.

\subsection{Characteristics of two-sided markets}

Different scholars describe the characteristics of bilateral markets from different dimensions and perspectives. To sum up, there are three aspects: One is Cross-network Externality, which is regarded as the source of the driving force of competition between platforms(Gawer[27], 2014); The second is the complementarity of the platform's bilateral demand. This feature has triggered the biggest debate in bilateral market theory: the chicken-egg problem (Rochet \& Tirole[20], 2003) ); The third is that the price structure is non-neutral. This feature opens up the research direction of the platform price mechanism.

\subsection{Classification of bilateral markets}

Different scholars divide the types of platforms from their own perspectives, which can be summarized into 
the following two categories: one is from the perspective of the market; the other is from the perspective of the platform.

Table 1 Classification of platforms

\begin{tabular}{|c|c|c|c|}
\hline \multirow{4}{*}{ Market perspective } & Pricing level & $\begin{array}{l}\text { Symmetric bilateral market } \\
\text { Asymmetric bilateral market }\end{array}$ & Evans, 2003 \\
\hline & $\begin{array}{l}\text { The number of } \\
\text { consumer groups }\end{array}$ & $\begin{array}{l}\text { Simple two-sided market } \\
\text { Complex two-sided market }\end{array}$ & Rochet\&Tirole, 2004 \\
\hline & Attributes & $\begin{array}{l}\text { Intermediary market } \\
\text { Audience maker market } \\
\text { Shared market } \\
\text { Market place }\end{array}$ & Hagiu, 2006 \\
\hline & Dimension & $\begin{array}{l}\text { Horizontal plattorm } \\
\text { Vertical platform }\end{array}$ & $\begin{array}{l}\text { Belleflamme\& } \\
\text { Toulemonde, } 2004\end{array}$ \\
\hline \multirow{5}{*}{$\begin{array}{l}\text { division of the } \\
\text { carrier }\end{array}$} & Level of competition & $\begin{array}{l}\text { Monopolist plattorm } \\
\text { Competitive plattorm } \\
\text { Competitive bottleneck } \\
\text { plattorm }\end{array}$ & Armstrong, 2010 \\
\hline & $\begin{array}{l}\text { Category level of } \\
\text { consumer groups }\end{array}$ & $\begin{array}{l}\text { Consistent plattorm } \\
\text { Cross plattorm } \\
\text { Monopoly platform }\end{array}$ & Evans, 2003 \\
\hline & \multirow{3}{*}{ Functional level } & $\begin{array}{l}\text { Price adjuster } \\
\text { Licensor } \\
\text { Competition governor }\end{array}$ & Rochet \& Tirole, 2004 \\
\hline & & $\begin{array}{l}\text { Market maker } \\
\text { Audience maker } \\
\text { Demand coordinator }\end{array}$ & Evans, 2003 \\
\hline & & $\begin{array}{l}\text { Transaction fee plattorm } \\
\text { No transaction fee platform }\end{array}$ & Filistrucchi, 2008 \\
\hline
\end{tabular}

From the perspective of the market, platforms are classified according to their pricing, the number of consumer groups, and market attributes. From the perspective of pricing, according to whether the twosided market is charged at the same time or only one side is charged, it is divided into a symmetrical bilateral market and an asymmetrical two-sided market (Evans[24], 2003); from the perspective of the number of consumer groups, according to consumers participating in the bilateral platform, types are divided into simple bilateral markets and complex bilateral markets. Only the three parties, the buyer, the seller and the platform provider, both participate in the two-sided market, which could be call two-sided market(Rochet \& Tirole[26], 2010); from the perspective of the attributes of the market, it can be divided into an intermediary market, an audience maker market, a shared input market, and a transaction market ( Hagiu[28], 2006). From the perspective of the market dimension, the platforms are divided into horizontal platforms and vertical platforms according to the relevance of the industries involved (Belleflamme \& Toulemonde[29], 2004).

From this perspective of the platform, scholars have classified the platforms according to the level of competition, the category and function of consumer groups. From the level of competition, it can be divided into monopolist platforms, competitive platforms, and potentially competitive bottleneck platforms (there is a multi-homing situation) (Armstrong[22], 2010); from the level of consumer groups, it is divided into coincident platforms, Intersecting platform, monopoly platform (Evans[24], 2003); from the functional level of the platform, it can be divided into price regulator, licensing authority, and competition authority (Rochet \& Tirole[26]). , 2010). Another classification method at the functional level is divided into market-makers, audience-makers, and demand coordinators (Evans[24], 2003). There is also a method that divides the platform into a platform with transaction fees and a platform without transaction fees according to whether the platform involves transaction fees (Filistrucchi[30], 2008).

\section{RESEARCH ON PLATFORMIZATION}

Driven by information technology, the transformative forces brought about by the platform economy have penetrated into all walks of life. The emergence of various platforms in the business field and social organizations has caused critics to use the term "Platformization" and promoted the emergence of a "platform society" based on a specific software as the infrastructure (van Dijck[31]). , 2017). Since the connotation covered by the term platform is much more than that it can express (Gillespie[32], 2010), it is necessary to explore the transformation of platform. Social media and other related digital services that are labeled as platforms not only facilitate social, economic, cultural, and political interactions, but also actually organize and drive these interactions (Nieborg \& Poell[33], 2018).

\subsection{The essence of Platformization}

Helmond[34] (2015), who first proposed the definition of platformization for network platforms, believes that platformization is the process by which platforms become the dominant structure and economic model in social networks. This process is dominated by the dual logic of decentralization and recentralization of the data prepared for the platform. And Islind et al.[35] (2016) more specifically referred to platformization as the socio-technical process of creating a platform. Bygstad \& Hanseth[36] (2018), from the perspective of technology definition, believes that platformization is a process in which specific information technology solutions (IT silo solutions) gradually turn to platformoriented digital infrastructure.

The transformative power brought by the platform is embodied by the concept of platformization in which the platform is driven as the dominant structure and economic model (Gustavsson[37], 2019). Rodon [38](2018) viewed platformization from the perspective of generative entrenchment. It is gradually accumulate and expand the functional layer in the scope of the original system, while continuously consolidating the original system. Nieborg \& Poell[33] (2018) defined the platform as a digital platform from the perspective of the cultural industry, which expands in the economic, management and basic information structure and 
penetrates into the network and APP ecosystem, thereby affecting the development of the industry. Judging from the explanations of the above-mentioned scholars, platformization cannot be simply seen as a transformation of the media economy from a traditional perspective. On the contrary, platformization is related to an organizational principle, similar to the Ford system and the Taylor system. It is gradually incorporating more various factors and coordinating the relationship between all participants, thereby guiding competition and independent relationships between each other (Schwarz \& Jonas[39], 2017).

\subsection{Platform-based research trends}

The emergence of the platform economy phenomenon must have its theoretical mechanism. Discovering the essence through the phenomenon is the core basis for further guiding and advancing the phenomenon. Therefore, many scholars have conducted related theoretical research on the mechanism of platformization. In the process of revealing the role of the platformization mechanism, many words and concepts in other fields are used to analyze the platformization mechanism. For example, the drifting information infrastructure is transformed into a digital platform. This is the platformization led by the information structure reform. Bygstad \& Hanseth[36] (2018) used digital infrastructures and IT silo solutions to explain and study the process of platformization. Rodon[38] (2018) explained the mechanism of platformization from the perspective of level consolidation (generative entrenchment), and believed that platformization is a process in which external construction levels gradually increase to expand the functions and scope of the existing system and consolidate the original system at the same time.

\section{CONCLUSION}

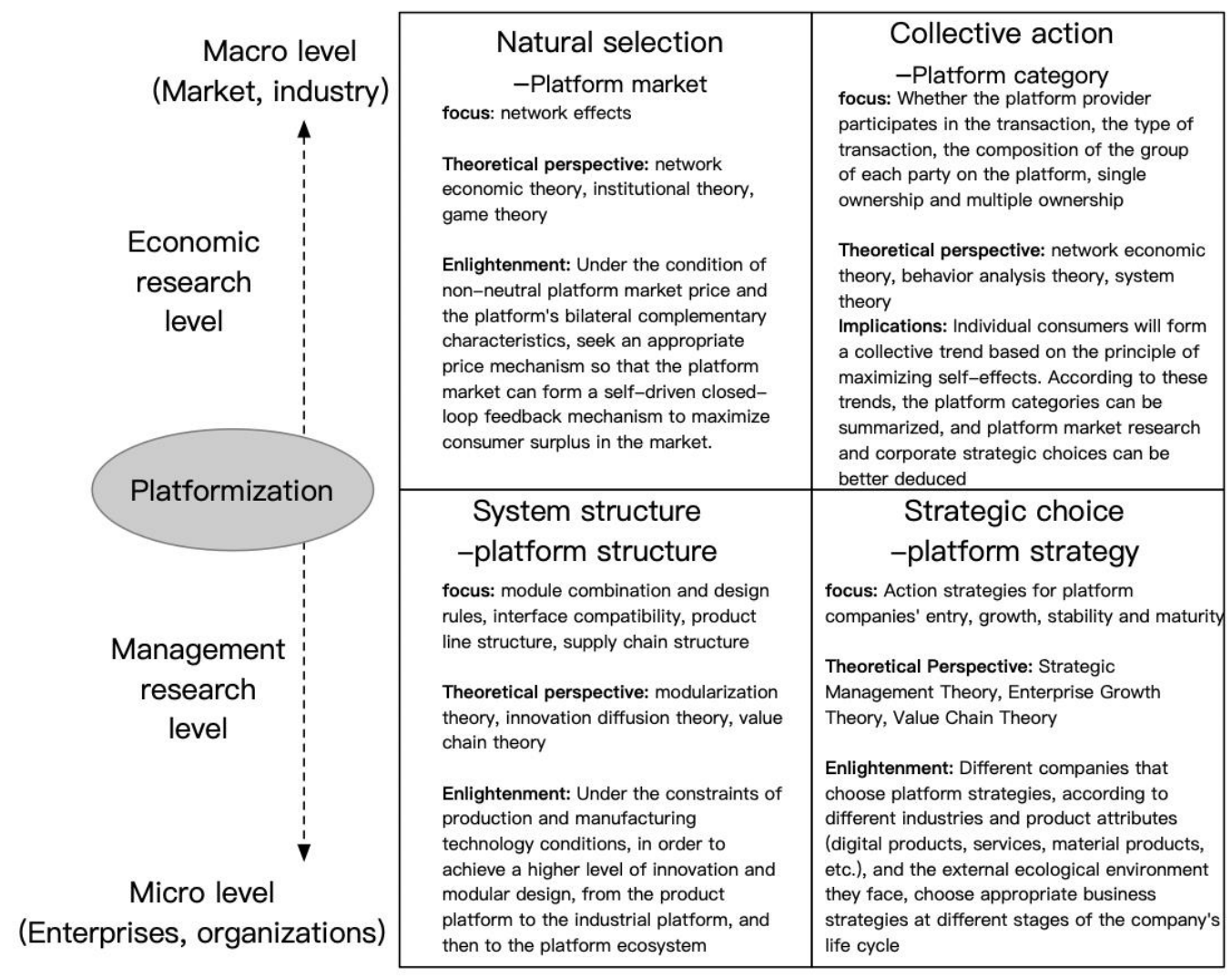

Deterministic orientation

Autonomy

Figure 2 Platform research under the framework of meta-theory

Summarizing the focuses of the literature from the perspectives of management, economics and platformation above, we can see that there are various perspectives and methods in the evolution of platform research. Astley and Van de Ven (1983) put forward the framework of meta-theory of organization theory that can be used to dialectically analyze various schools' endlessly debated. Within the framework the related research of platform economy can be divided into four main categories from micro-macro (economicsmanagement) and certainty-autonomy (the two dimensions): system structure perspective, strategy Selection perspective, collective action perspective and natural selection perspective. 
From the perspective of system structure, platform research focuses on the structure of the platform, starting from the product platform at the micro level, gradually evolving to the platform ecosystem at the macro level, and gradually cross-integrating with the platform market focused by the perspective of natural selection; while the perspective of strategic choice focuses on platform strategy, and companies continue to create strategies, whose deterministic orientation generated by technological constraints gradually transitions to an autonomous orientation; The collective action perspective focuses on the research of platform categories. The research on macro-level category classification has a supporting effect on the research of micro-level platform strategy and the research on the deterministic orientation of the platform market under the constraints of network effects.

The same concept---platform come into being the object of research from different fields, and finally cross-integrated at multiple points.

Table 2 Comparison of platform research in the field of management and economics

\begin{tabular}{|c|c|c|}
\hline field & management & economics \\
\hline concept & $\begin{array}{l}\text { Production technology structure as a } \\
\text { platform }\end{array}$ & Market as a platform \\
\hline Dimension & Supply side & Supply-side and demand-side \\
\hline focus & Innovation & competition \\
\hline The origin of the theory & Modular theory & Intermediate Organization Theory \\
\hline Source of value creation & combination & Network externalities \\
\hline Roles & Coordinator of innovative technology & Coordinator of buyer and seller \\
\hline Source of effect & \multicolumn{2}{|c|}{$\begin{array}{c}\text { Economics of Scope and Expansion of Scale Brought by Information Network } \\
\text { Technology }\end{array}$} \\
\hline solved problem & Reduce costs and innovation risks & Information asymmetry \\
\hline Coordination mechanism & contract & price \\
\hline Governance issues & Network regulations, information security & Monopoly issues, tax issues \\
\hline Research trends & $\begin{array}{c}\text { Internal platform }->\text { External platform - } \\
>\text { System platform } \\
\text { Small range }->\text { Large range }\end{array}$ & $\begin{array}{l}\text { Theory construction } \rightarrow>\text { specific issues } \\
\quad \rightarrow>\text { revised theory }\end{array}$ \\
\hline Fusion point & \multicolumn{2}{|c|}{ The entry of platform companies and the company's competitive strategy } \\
\hline
\end{tabular}

Although the concepts, focus, theoretical origins, value sources, and roles played by platforms are different in these two different fields, with the continuous deepening of disciplinary research, there are at least the following points of intersection between the two fields: 1.Role intersection. From the perspective of the research context of the two fields, management research has continued to expand from a small scale, and the level and scope of the platform have also continued to expand. When the platform from the perspective of management expands to be a link in the industrial chain, it is expanded to serve as a market and to be one of the participants, it began to overlap with the platform role of economics. 2.the intersection of solving problem. The practical problems that the two fields are concerned about also overlap. Management mainly solves the cost and risk of innovation. When the enterprise itself is used as a module or as a platform, solving information asymmetry has also become an important task for the enterprise. 3. Intersection point of coordination mechanism. Economics is concerned with price, but from the point of view of its origin, price is only a quantitative form of contract, and it can also be seen as an intersection. 4. Intersection of effect sources. The modular combination in management has brought innovation, and the indirect network effect brought about by the complementarity of all parties through the market in economics. Both of two sources of the effect has benefited from the technological progress brought about by the development of information networks.

The above-mentioned intersections eventually led to the integration of the two fields. Research in the related fields of platformization is based on the theoretical basis of management and economics. Under the guidance of actual production activities and business development processes, the research on platformization of direction and content are undergoing, and finally all settle on issues such as the entry of platform companies, the issues of corporate competitive strategy, platform governance, platform application in the field of public management, and platform transformation. Therefore, this article believes that research on platform economy can be further explored from the following aspects in the future:

First, in-depth research on the development of platform competition. Previous studies believe that market platforms in the digital field tend to evolve toward a dominant one. Under certain conditions, a strong network effect tends to lead to a win in competition among platforms. The end of the take-all. In fact, a single big (integration) is not necessary to solve the platform coordination problem, even if it can be solved, but not sufficient. In the commercial field, all platforms change their platform strategies towards reverse integration when the platforms are large enough and mature enough. In actual business practice, there are also cases where large platform companies split their platform businesses into small one. Therefore, from the perspective of management, the research on the motivation, conditions and levels of reverse integration of platform companies is of great significance. From the perspective of economics, this issue also has practical significance. Under the condition of certain equilibrium, since there will always be more effective substitute producers who will enter the market and will always adopt effective strategies to weaken the market position of the incumbent producers and the network effect cannot promote the firm's market position. So bilateral platforms are not always superior to other market structures. Even when the two-sided market is the optimal choice, we also need to consider whether it is socially optimal, so as to integrate the other side or more on the platform. There is no end to this research topic, especially for many digital platforms that operate in a 
unilateral mode of the traditional market. In addition, for Hagiu and other scholars on the question of platform integration or splitting the role of bilateral platform investment, it is particularly necessary to establish a more complex model to solve this important issue.

Second, in-depth research on platform market classification. Although there have been many researches on the classification of the platform market, many scholars have classified platforms according to different dimensions, but compared with the research on other characteristics of the platform market, the classification of the platform has not been researched in place. Judging from the summary of various scholars' classifications of platform types in this article, most of these classifications are done to meet the needs of authors for analyzing specific issues (such as starting an antitrust analysis) or building models. It is helpful for us to understand the market from different perspectives. As the market continues to evolve, a new classification method is necessary no matter from a management research perspective or an economic research perspective, especially for the digital platform market. The services and products of digital platforms are provided on the basis of the network, and the variability of products is significant. There is no corresponding result for the platform market classification in this field.

Third, the barriers to entry and monopoly of platform companies. With the rapid rise of the platform economy, in addition to the perspective of business participants (consumers, producers, platform providers, network providers, etc.). At the same time, the platform operation process and mechanism are studied from multiple dimensions of the core elements of economic operation(such as time division, price, information symmetry, etc.).Another research direction is becoming more and more important, that is, how to look at the laws and policies related to the platform market from the perspective of the government (such as the coordination between the intellectual property policy and the level of platform openness is an important branch. In previous studies, most of the market entry of platform companies is studied from the perspectives of management and economics, and the entry barriers are mainly analyzed from the perspective of enterprises, but there is no analysis of entry barriers and monopolies from the perspective of the government. There are still many issues worthy of research, such as the classical vendors in the market. What is the role of the emerging platform? With the rise of the platform economy, more and more industries have penetrated into it, and related platform policies have been introduced one after another. However, there are still great deficiencies in policies aimed at entry barriers and resulting monopoly issues.

\section{REFERENCES}

[1] Wheelwright,S.C.,Clark K.B. Creating Project Plans to Focus Product Development [J]. Harvard Business Review,1992,70(2).

[2] Mcgrath M E. Product Strategy for High-technology Companies[J]. Research Technology Management, 1995, 38(4):275-278.

[3] Meyer MH Lehnerd A P. The Power of Product Platforms Building Value \& Cost Leadership[M]. New York Free Press 1997.

[4] Krishnan V, Gupta S. Appropriateness \& Impact of Platform-Based Product Development[J]. Management Science, 2001, 47(1):52-68.

[5] Muffatto M, Roveda M. Product architecture \& platforms: a conceptual framework[J]. Proceedings of Research Seminar on the Management of Innovation \& New Product Development, 2002, 24(24):1-16.

[6] Kulatilaka K N. Options Thinking \& Platform Investments: Investing in Opportunity[J]. California Management Review, 1994, 36(2):5271.

[7] Kim D J, Kogut B. Technological Platforms \& Diversification[J]. Organization Science, 1996, 7(3):283-301.

[8] Sawhney M S. Leveraged high-variety strategies: From portfolio thinking to platform thinking $[\mathrm{J}]$. Journal of the Academy of Marketing Science, 1998, 26(1):54

[9] Sanderson S, Uzumeri M. Managing product families: The case of the Sony Walkman[J]. Research Policy, 1995, 24(5):761-782.

[10] Robertson, David \& Karl Ulrich, Planning for product platforms[J]. Sloan Management Review,1998,39 (4):19-31.

[11] Panzar J C, Willig R D. Economies of Scope[J]. American Economic Review, 1981, 71(2):268-272.

[12] Teece D J . Economies of scope \& the scope of the enterprise $[\mathrm{J}]$. Journal of Economic Behavior \& Organization, 2006, 1(3):223-247.

[13] Zirpoli F, Becker M C. The limits of design \& engineering outsourcing: performance integration \& the unfulfilled promises of modularity[J]. R \& D Management, 2011, 41(1):21-43.

[14] Hatch N W. Design Rules, Volume 1: The Power of Modularity by Carliss Y. Baldwin; Kim B. Clark[J]. Academy of Management Review, 2001, 26(1):130-133. 
[15] Baldwin C Y,Woodard C J. The architecture of platforms: a unified view[J]. Harvard Business School Finance Working Paper,2009(34).

[16] Adner R, Kapoor R. Value creation in innovation ecosystems: how the structure of technological interdependence affects firm performance in new technology generations[J]. Strategic Management Journal, 2010, 31(3):306-333.

[17] Dougherty D. Organizing for innovation in complex innovation systems[J]. Innovation Management Policy \& Practice, 2017, 19(1):11-15.

[18] Gawer A. Platforms, markets \& innovation[M]. 2009.

[19] Rochet J C, Tirole J. Platform Competition in TwoSided Markets[J]. Journal of the European Economic Association, 2003, 1(4):990-1029.

[20] Caillaud B, Jullien B. Chicken \& Egg: Competition among Intermediation Service Providers[J]. R\& Journal of Economics, 2003, 34(2):309-328.

[21] Ambrus A, Argenziano R. Network Markets \& Consumer Coordination[J]. Social Science Electronic Publishing, 2004(10).

[22] Armstrong M. Competition in two-sided markets[J]. R\& Journal of Economics, 2010, 37(3):668-691.

[23] Chakravorti S, Roson R. Platform Competition in Two-Sided Markets: The Case of Payment Networks[J]. Review of Network Economics, 2006, 5(1):118-143.

[24] Evans D S. Some Empirical Aspects of Multi-sided Platform Industries[J]. Social Science Electronic Publishing, 2003, 2(3):191-209.

[25] Rysman M. The Economics of Two-Sided Markets[J]. Journal of Economic Perspectives, 2009, 23(3):125-143.

[26] Rochet J C, Tirole J. Two-Sided Markets: A Progress Report[J]. R\& Journal of Economics, 2010, 37 (3):645-667.

[27] Annabele Gawer.Bridging Difering Perspectives on the Technological Platform:Toward an IntegrativeFramework [J].Research Policy,2014,1239-1249.

[28] Hagiu A. Pricing \& Commitment by Two-Sided Platforms[J]. R\& Journal of Economics, 2006, 37(3):720-737.

[29] Belleflamme P, Toulemonde E. Emergence \& entry of B2B marketplaces[J]. CORE Discussion, 2004.
[30] Filistrucchi L . A SSNIP test for two-sided markets: the case of media[J]. SSRN Electronic Journal, 2008, 08-34(8-34).

[31] Van Dijck J, Poell T, De Waal M. The platform society: Public values in a connective world[M]. Oxford University Press, 2018.

[32] Gillespie T. The politics of 'platforms'[J]. New media \& society, 2010, 12(3): 347-364.

[33] Nieborg D B, Poell T. The platformization of cultural production: Theorizing the contingent cultural commodity[J]. New Media \& Society, 2018, 20(11): 4275-4292.

[34] Helmand A. The platformization of the web: Making web data platform ready[J]. Social Media+ Society, 2015, 1(2): 1-11.

[35] Islind A S, Lindroth T, Snis U L, et al. Co-creation and fine-tuning of boundary resources in smallscale platformization[C]//Scandinavian Conference on Information Systems. Springer, Cham, 2016: 149-162.

[36] Bygstad B, Hanseth O. Transforming Digital Infrastructures through platformization[C]//ECIS. 2018: 74.

[37] Gustavsson M, Ljungberg J. Platformization of a Cloud Service[J]. 2019.

[38] Rodon, Joan.Platformization as Generative Entrenchment: A Case of a Public Heaclthcare System[J]2018.

[39] Schwarz A, Jonas. Platform Logic: An Interdisciplinary Approach to the Platform-Based Economy[J]. Policy \& Internet, 2017.9(4): 374394. 